REVIEW ARTICLE

\title{
Dendritic cell functions in the inductive and effector sites
} \section{of intestinal immunity}

\author{
Cécilia Luciani ${ }^{1}$, Fabian Tobias Hager ${ }^{2}$, Vuk Cerovic ${ }^{2 \bowtie}$ and Hugues Lelouard ${ }^{1 凶}$ \\ (c) The Author(s), under exclusive licence to Society for Mucosal Immunology 2021
}

The intestine is constantly exposed to foreign antigens, which are mostly innocuous but can sometimes be harmful. Therefore, the intestinal immune system has the delicate task of maintaining immune tolerance to harmless food antigens while inducing tailored immune responses to pathogens and regulating but tolerating the microbiota. Intestinal dendritic cells (DCs) play a central role in these functions as sentinel cells able to prime and polarize the T cell responses. DCs are deployed throughout the intestinal mucosa but with local specializations along the gut length and between the diffuse effector sites of the gut lamina propria (LP) and the wellorganized immune inductive sites comprising isolated lymphoid follicles (ILFs), Peyer's patches (PPs), and other species-specific gutassociated lymphoid tissues (GALTs). Understanding the specificities of each intestinal DC subset, how environmental factors influence DC functions, and how these can be modulated is key to harnessing the therapeutic potential of mucosal adaptive immune responses, whether by enhancing the efficacy of mucosal vaccines or by increasing tolerogenic responses in inflammatory disorders. In this review, we summarize recent findings related to intestinal DCs in steady state and upon inflammation, with a special focus on their functional specializations, highly dependent on their microenvironment.

Mucosal Immunology (2022) 15:40-50; https://doi.org/10.1038/s41385-021-00448-w

\section{INTRODUCTION}

The intestinal immune system maintains a delicate balance between the induction of immunity to pathogens and maintenance of immune tolerance to innocuous gut antigens, such as those derived from food or commensal bacteria ${ }^{1,2}$. Crucial for this equilibrium are dendritic cells (DCs) which are professional antigen-presenting cells (APCs) that act as central regulators of immunity and tolerance. As the name "dendritic cells" has been given to different cell types, the general consensus in the field is to refer to the main professional APC population as classical or conventional DCs (cDCs) to avoid confusion with other cell types that bear the name $\mathrm{DC}^{3}$. It is worth noting that plasmacytoid DCs (pDCs) differ from cDCs in ontogeny and function, do not migrate in lymph, and most likely do not contribute significantly to antigen presentation and priming ${ }^{4,5}$. As such, they will not be discussed further in this review. By contrast, tissue CDCs migrate from the periphery to local lymph nodes (LNs) where they present antigen to T cells. Uniquely among APCs, CDCs can prime naïve T cells and induce their differentiation and polarization towards an inflammatory or regulatory phenotype. Therefore, CDCs represent a key link between the activation of the innate and adaptive immune systems as well as an anatomical link by which antigen and various signals are transmitted from the peripheral to lymphoid tissues.

In the intestine, $C D C s$ are located scattered throughout the lamina propria (LP) but are also concentrated in defined regions of Peyer's patches (PPs), isolated lymphoid follicles (ILFs), and other species-specific gut-associated lymphoid tissues (GALTs). While they share many phenotypic and functional properties, CDCs at these different sites have distinct features and functions that act in concert to orchestrate the intestinal immune response.

Intestinal CDCs act as immune sentinels in both GALTs and LP $P^{6,7}$. They are seeded from blood-borne precursors, which differentiate into immature $\mathrm{CDCs}$ that are thought to reside 7 to 10 days in the intestine. During this time, cDCs acquire antigens from the intestinal lumen for later presentation. Unlike macrophages, upon maturation or activation, LP CDCs upregulate the chemokine receptor CCR7 and migrate to the intestine-draining mesenteric lymph nodes (MLNs), a chain of discrete LNs localized in the mesentery, where they present antigens to naïve $T$ cells $s^{8,9}$. Similarly, PP CDCs upregulate CCR7 and migrate to the interfollicular regions (IFRs) of PPs, where they interact and present antigen to naïve $T$ cells ${ }^{10,11}$. Crucially, based on signals from their initial microenvironment, these migratory $\mathrm{CDCs}$ are able to instruct the polarization of the developing T cell response, which is one of the key mechanisms controlling the balance between tolerance and immunity in the intestine ${ }^{12}$.

In this review, we will summarize the current knowledge on the biology of intestinal CDC as they are the principal APCs responsible for the priming of naïve T cells. We primarily focus on phenotypic and functional properties of mouse intestinal CDCs as the majority of our understanding comes from the murine model. However, we highlight specific results obtained from human studies, where appropriate. Since some monocyte-derived phagocytes may contribute and/or play a complementary role to $\mathrm{CDC}$ functions, especially in PP, where one specific monocyte-derived phagocyte

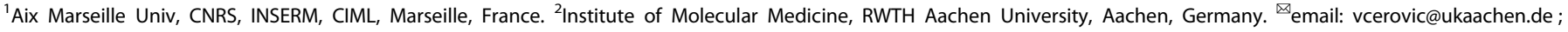
lelouard@ciml.univ-mrs.fr

Received: 29 April 2021 Revised: 9 August 2021 Accepted: 15 August 2021

Published online: 31 August 2021 
Table 1. Mouse intestinal phagocyte markers.
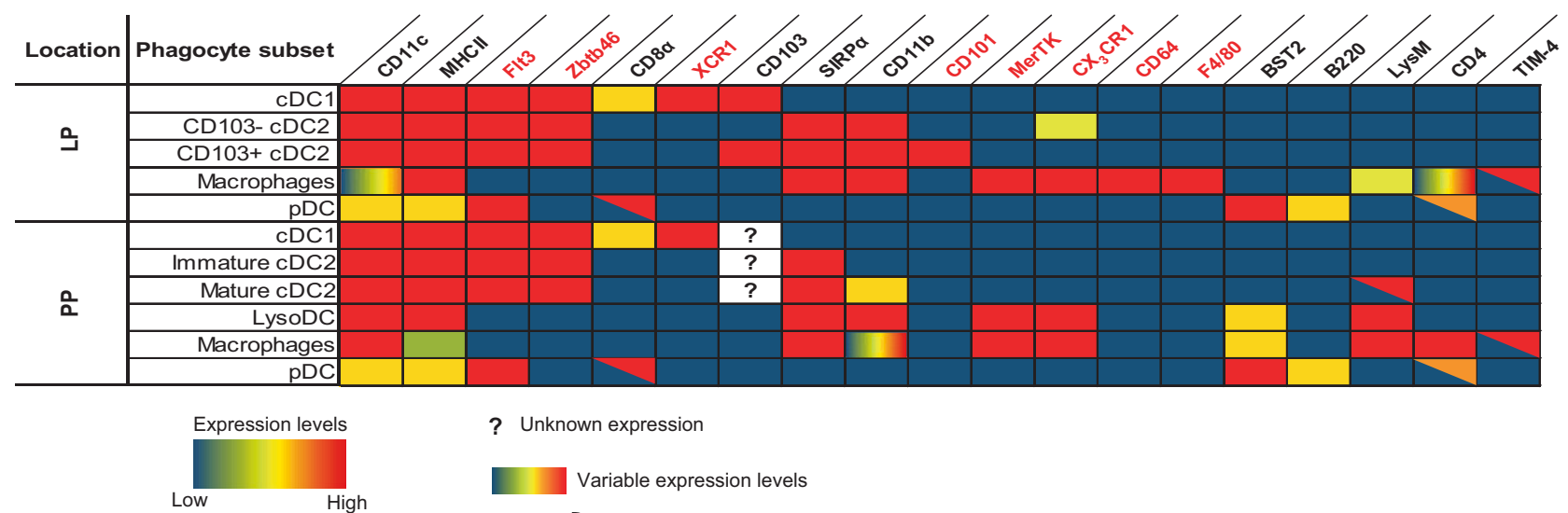

? Unknown expression

Variable expression levels

- $\}$ Population with subsets expressing or not the marker

subset, termed LysoDC, shares many functional properties with $\mathrm{CDCs}^{11,13}$, we will also describe the functional specificities of these cells. Finally, we will discuss the pending questions concerning the respective contribution of each $\mathrm{CDC}$ subset to the regulation of the intestinal immune system.

\section{PHENOTYPE OF INTESTINAL CDCS}

As in other tissues, intestinal CDCs have originally been identified by the surface expression of the antigen-presenting molecule, class II major histocompatibility complex (MHCII), and the alpha-x integrin, CD11c. However, these two markers are also expressed by intestinal macrophages, necessitating the use of specific macrophage markers such as Mer tyrosine kinase (MerTK) and specific CDC markers such as fms-like tyrosine kinase 3 (Flt3) and the transcription factor Zbtb46 to unambiguously distinguish the two cell types (Table 1) ${ }^{14,15}$. CX ${ }_{3} \mathrm{CR} 1$, which had been proposed as a macrophage-specific marker, is less reliable, as it can be expressed both in the small intestine and the colon by a subset of CD103- LP CDCs, although at lower levels than in macrophages $^{16-18}$. In addition, F4/80 and CD64 are specific macrophage markers that can be used to distinguish CDCs from macrophages in the $L P^{17,19}$ but not in PP where they are not expressed on macrophages (Table 1) ${ }^{13,15}$. It should be noted that CD64 appears also absent from a minor population of macrophages in the colonic LP $^{20}$ and has been shown to be expressed by a subset of lung CDCs under inflammatory conditions ${ }^{21}$. Although such inflammatory $\mathrm{CDCs}$ have not yet been detected in the intestine, these observations necessitate caution when using CD64 alone as a definitive macrophage marker.

Intestinal $\mathrm{cDCs}$ are heterogeneous and comprise two main subpopulations, termed $\mathrm{CDC} 1$ and $\mathrm{CDC} 2^{3}$. These represent the two developmentally, phenotypically, and functionally distinct CDC lineages which can be distinguished in both mouse and human tissues by the expression of the chemokine receptor XCR1 and CD172a (SIRPa), respectively ${ }^{22,23}$. However, whereas XCR1 represents a specific marker of $\mathrm{CDC} 1 \mathrm{~s}$, mouse $\mathrm{CDC} 2 \mathrm{~s}$ share expression of CD172a as well as other markers, such as the alpha-M integrin CD11b, with macrophages (Table 1). Therefore, caution must be taken when interpreting data that do not include specific CDC and macrophage markers in addition to CD172a, CD11c, CD11b, and MHCII. In the mouse intestinal LP, in addition to XCR1, CDC1s express CD103, CD8a, Clec9a, TLR3 and lack expression of CD11b and $C D 172 a^{24,25}$. Unlike $C D C 1 s$, intestinal $C D C 2 s$ are a heterogeneous population, which makes their identification and functional studies more difficult. Thus, in mouse PPs, CDC2s express lower levels of CD11b than in the LP and immature PP CDC2s even lack CD11b expression ${ }^{10}$. By contrast, in the mouse LP, CDC2 universally express CD172a and CD11b but have a heterogeneous expression of $\mathrm{CD} 103$ and $\mathrm{CX}_{3} \mathrm{CR} 1^{16-18}$. In the small intestinal (SI) LP, the majority of CDC2s express CD103, while a smaller population lack CD103 and express intermediate levels of $\mathrm{CX}_{3} \mathrm{CR} 1^{16,17}$. This ratio is reversed in the colonic $\mathrm{LP}^{\mathrm{w}}$ where $\mathrm{CD} 103^{-}$ CDC2s form the majority of the CDC2 compartment ${ }^{18}$. Recently, an additional subpopulation of colonic LP $\mathrm{CDC} 2 \mathrm{~s}$ has been identified based on the expression of CD26 and CD14 ${ }^{20}$.

Analogous subsets can be identified in the human intestinal LP. In addition to XCR1, human CDC1s also express CD141 while the CDC2 population shows an expression of CD172a and CD1C and, like in the mouse, can be subdivided based on $C D 103^{26,27}$. Similar to the mouse intestine, $\mathrm{CD} 103^{+} \mathrm{CDC} 2$ numbers decrease in favor of $\mathrm{CD}_{103^{-}} \mathrm{CDC} 2$ in the human colon as compared to the small intestine ${ }^{27}$.

\section{ONTOGENY OF LP CDCS}

The development of LP CDC subsets broadly reflects the ontogeny of $\mathrm{CDC} 1 \mathrm{~s}$ and $\mathrm{CDC} 2 \mathrm{~s}$ described in other tissues ${ }^{28}$. All LP $\mathrm{CDCs}$ express the prototypical DC transcription factor Zbtb46, accumulate after administration of the DC growth factor Flt3 ligand (Flt3L), and are absent in Flt3 or Flt3L deficient mice ${ }^{16,17,29-32}$. All subsets of LP CDCs develop from committed pre-DC precursors ${ }^{17,29,33}$.

LP CDC1 development depends on the transcription factors IRF8, Batf3, and Id2, which control the expression of typical CDC1 genes such as XCR1, CD8a, and Clec9 $a^{34,35}$. In contrast, the mechanisms controlling $C D C 2$ development are less well understood, but maintenance of $\mathrm{LP} \mathrm{CDC} 2 \mathrm{~s}$ is at least partially dependent on the transcription factors IRF4 and KLF4. Thus, the number of CDC2s is reduced in the SI LP and severely depleted in the MLN of conditional knock-outs of IRF4 in CD11c-expressing cells, demonstrating the crucial role of IRF4 in intestinal CDC2 survival and potentially development ${ }^{26,36}$. Similarly, conditional depletion of KLF4 in CD11c-expressing cells reduces the expression of IRF4 in CDC progenitors and results in the selective reduction of SI LP $\mathrm{CDC} 2 \mathrm{~s}^{37}$. Additionally, the numbers of LP CDC2s are markedly reduced in mice with disrupted Notch2 signaling ${ }^{38,39}$ and in CSF2 

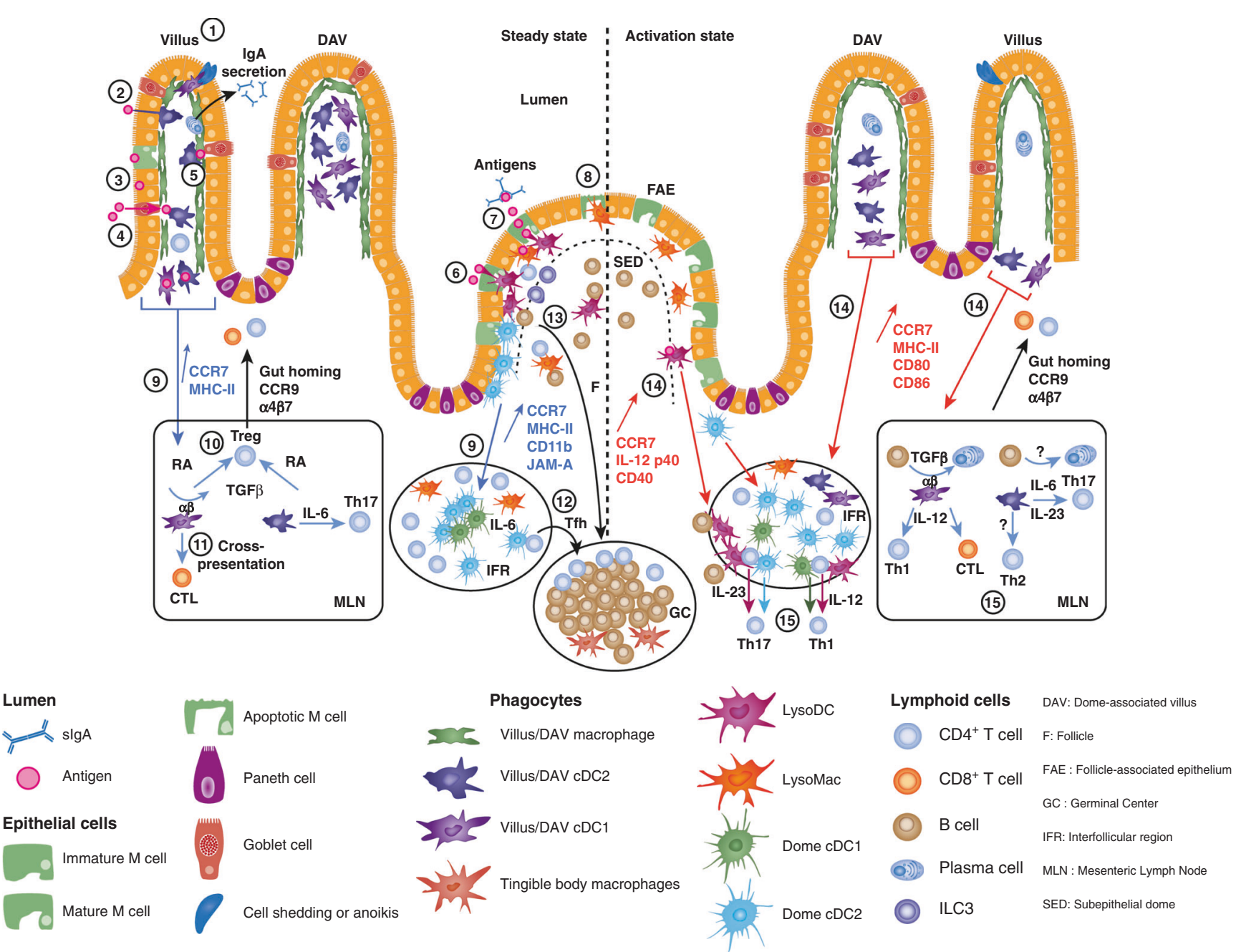

Fig. 1 Functions of villus and Peyer's patch dendritic cells in the induction of tolerance and immunity. Intestinal luminal antigen acquisition by DCs can occur through several mechanisms in both the effector (1 to 5) and the inductive sites (6 to 8 ) of intestinal immunity. (1) In villi, CDC1 can internalize materials, including self-antigens, from dying epithelial cells. (2) CD103 ${ }^{+}$cDCs can extend paracellular transepithelial dendrites to sample luminal antigens. (3) Rare villus $\mathrm{M}$ cells or paracellular transepithelial leakage could also contribute to antigen acquisition by CDC. (4) Finally, goblet cell-associated antigen passages allow the antigen to cross the epithelial barrier to be taken up by DCs and macrophages, thereby promoting their tolerogenic properties and supporting tolerance to dietary antigens. This mechanism seems to be dominant over the others. (5) Additionally, antigens that had been internalized by macrophages can be transferred to cDCs via gap junctions. In Peyer's patches (PPs), the specific properties of the follicle-associated epithelium (FAE) (lack of mucus, antimicrobial peptides and IgA secretion, attenuated glycocalyx, specialized antigen-transporting $M$ cells) facilitate access to larger antigens, including viruses and bacteria, compared to villus epithelium. Like in villi, several mechanisms of uptake exist but they all depend on M cells. (6) LysoDCs can extend dendrites through $\mathrm{M}$ cell-specific transcellular pores to sample luminal antigens including pathogenic bacteria, before retracting back to the subepithelial dome (SED). (7) M cells transport many types of antigens to the SED or to their basolateral membrane invagination containing CDC2s, LysoDCs, and lymphoid cells. They also release toward the SED vesicles and IgA-opsonized antigens that are taken up by subepithelial LysoDCs and macrophages. (8) Finally, dying M cells containing internalized antigens are phagocytosed by LysoDCs and macrophages. (9) Following antigen sampling, villus CDCs and SED CDC2s but not LysoDCs constitutively migrate to the mesenteric lymph nodes (MLNs) and the interfollicular regions (IFRs), respectively. In steady state, migratory CDCs present antigens in the MLN to naïve CD4 ${ }^{+}$and CD8 ${ }^{+} \mathrm{T}_{\text {cells in a }}$ tolerogenic manner. (10) Thus, their production of retinoic acid (RA) allows the generation of regulatory T cells (Tregs) that express the guthoming molecules CCR9 and $\alpha 4 \beta 7$ integrin. In addition, CDC1s express the $\alpha v \beta 8$ integrin that converts transforming growth factor- $\beta$ (TGF $\beta$ ) into its active form, which contributes to Treg generation. (11) Finally, cross-presentation of antigens by cDC1s allows the generation of cytotoxic T lymphocytes (CTLs). (12) In PP IFRs, SED-emigrated CDC2s likely drive the differentiation of follicular helper T cells that are essential for germinal center formation and generation of antigen-specific high-affinity IgA-producing cells. (13) Interaction of B cells with cDC2s or LysoDCs in the SED promotes their class switch to IgA prior to their migration into the germinal center (GC). (14) Upon stimulation leading to their activation, villus $C D C 1 s$ and $C D C 2 s$ and dome-associated villus (DAV) CDC2s massively migrate into the MLNs and the IFRs, respectively. LysoDCs migrate to the periphery of the IFR, with a delay. (15) Activated CDCs and LysoDCs produce inflammatory cytokines promoting the differentiation of effector $T$ cells as indicated. $\mathbf{F}$, follicle.

receptor-deficient mice ${ }^{40}$. There is uncertainty about the developmental relationship of the two $\mathrm{CDC2}$ subpopulations present in the LP. CD103- LP CDC2s appear less affected by CD11c-targeted deletion of IRF4 than their CD103 ${ }^{+}$counterparts $^{26}$, and expand proportionally more upon treatment with $\mathrm{Flt}^{3} \mathrm{~L}^{16}$. While this could suggest that the two CDC2s subsets have distinct developmental requirements, a more likely explanation could be that $\mathrm{CD}_{103^{-}}$ $C D C 2 s$ represent an earlier developmental stage, which may give rise to $\mathrm{CD}_{103^{+}} \mathrm{CDC} 2 \mathrm{~s}$. In line with this, the CD103 ${ }^{+} \mathrm{SI} \mathrm{LP} \mathrm{CDC} 2 \mathrm{~s}$ have an overall transcriptional signature similar to that of $\mathrm{CD}_{103^{-}}$ 
$\mathrm{CDC2s}$, but show expression of genes atypical of the $\mathrm{CDC2}$ lineage, such as CD103, CD101, and Siglec $F^{41}$. The CD103 ${ }^{+}$phenotype of LP CDC2s is partially controlled by TGF $\beta$, Runx/Cbf $\beta$, and RA signaling ${ }^{33,41,42}$ and thus likely represents an example of tissuespecific conditioning, resulting in two subsets of $\mathrm{CDC} 2 \mathrm{~s}$, which exhibit functional differences, as discussed below.

More controversially, it has also been suggested that replenishment by blood monocytes may contribute to the LP DC pool. Indeed, in vitro, monocytes can be differentiated into cells with the phenotypic properties of $\mathrm{cDCs}$, including expression of Zbtb46 $6^{31}$, while monocyte lineage tracking potentially suggests that they may make a small contribution to steady-state $\mathrm{CDCs}^{43}$. Moreover, at least some of the $\mathrm{CD}_{103^{-}} \mathrm{LP}$ CDC2s express CCR2, possibly indicating a monocyte origin ${ }^{17}$. However, in transfer experiments, CDCs overwhelmingly develop from pre-DCs whereas monocytes give rise to intestinal macrophages ${ }^{17,29,44}$. Thus, the bulk of the evidence points to dedicated pre-DCs as the main gut $\mathrm{CDC}$ progenitors while leaving open the possibility of a minor contribution by monocytes.

\section{LP CDC FUNCTIONS}

\section{Antigen acquisition}

Several mechanisms by which LP CDCs can acquire luminal antigen have been proposed and observed, although their relative importance in vivo is still a subject of much debate (Fig. 1). A soluble antigen may reach LP CDCs via transcellular or paracellular transport across the epithelium ${ }^{45}$, while particulate antigen uptake may occur through isolated villus $\mathrm{M}$ cells ${ }^{46}$. Notably, a series of publications demonstrated that goblet cells can form so-called Goblet cell Associated Passages ("GAPs") that transport both soluble and particulate antigens to $C D 11 c^{+}$cells in the SI LP ${ }^{47-49}$. The inhibition of GAP formation has functional effects consistent with the loss of antigen presentation and priming capacity of SI LP CDCs, both in the induction of tolerance and immunity. Interestingly, the formation of GAPs in the colon is inhibited by microbial products and may be tightly regulated to limit microbiota and pathogen penetration and prevent overstimulation of the immune system while preserving tolerance induction in early life ${ }^{48,50,51}$. Other mechanisms of antigen acquisition, such as direct sampling of luminal antigen by intestinal macrophages and $\mathrm{CDCs}$, by extension of processes between cells of the intestinal epithelium ${ }^{52,53}$ as well as antigen transfer from LP macrophages to $\mathrm{CDCs}^{54}$ still require further functional characterization to fully clarify their contribution to antigen uptake by gut $\mathrm{CDCs}$ in vivo. In addition to luminal antigens, LP CDCs can also acquire self-antigens from apoptotic epithelial cells ${ }^{25,55}$.

\section{Migration}

While some antigens are able to passively diffuse from peripheral tissue to draining LNs, initiation of de novo immune or tolerogenic $\mathrm{T}$ cell responses crucially depends on carriage and presentation of antigens by $\mathrm{CDCs}^{9,56}$. Migration from peripheral tissues to draining $\mathrm{LNs}$ is the defining property of peripheral $\mathrm{CDCs}$ and central to their function. Accordingly, all subsets of LP CDCs can be detected in intestinal lymph ${ }^{16,18}$, as well as within the $\mathrm{MHCI}^{\text {hi }} \mathrm{CD} 11 \mathrm{c}^{\text {int }}$ population of migratory $\mathrm{CDCs}$ in the draining $\mathrm{MLN}^{25,26}$.

LP CDCs are present in the small intestine and colon in an immature state, in which they sample antigen from their environment. Eventually, CDCs undergo maturation and upregulate the C-C chemokine receptor 7 (CCR7), which interacts with its ligand CCL21 on lymphatic endothelial cells. This interaction enables CDC entry into lymphatic vessels and directed migration towards the draining lymph node, in both steady state and inflammation ${ }^{57,58}$. Interaction with CCR7 ligands also enables migrating $\mathrm{CDCs}$ to enter the LN T cell zones, which facilitates antigen presentation ${ }^{59,60}$.
Most studies on intestinal CDC migration have analysed socalled induced or inflammatory $\mathrm{CDC}$ migration by activation of Toll-like receptors (TLRs). For instance, oral administration of the TLR7 ligand R848 leads to massive recruitment of LP CDCs and an increase of migratory $C D C s$ in the intestinal lymph and $M L N s^{61,62}$. Similar effects were observed after activation of TLR3 by poly $1: C^{63}$. In both cases, activation and migration of CDCs from the LP was primarily the result of indirect activation via interferon type I or TNFa produced by $\mathrm{pDCs}^{62-64}$. Interestingly, although type I interferon leads to the activation of both $\mathrm{CDC} 1 \mathrm{~s}$ and $\mathrm{CDC} 2 \mathrm{~s}$, only CDC1s critically depend on direct type I interferon signaling for the migration induced by both TLR3 and TLR7 ligands ${ }^{63}$.

In contrast, the mechanisms controlling steady-state cDCs migration are still not fully understood, despite its importance in inducing peripheral tolerance to self- or orally fed antigen ${ }^{9}$. Indeed, cDCs continually migrate from the $L P$, through the lymphatics, to the draining MLN in a CCR7-dependent manner, even in the absence of overt stimulation ${ }^{16,18,65}$. It has been proposed that this steady-state $\mathrm{CDC}$ migration may depend on low-level stimulation by bacterial components continually present in the gut mucosa. Indeed, disruption of TLR signaling in MyD88 deficient mice leads to a reduced amount of migrating $C D C s$ in the steady-state $\mathrm{MLNs}^{66}$. Similarly, blockade of NF-KB signaling in CDCs results in a reduction of steady-state $\mathrm{CDC}$ migration and a decrease in induction of Foxp $3^{+}$regulatory T cells (Tregs) ${ }^{67}$. However, steadystate LP CDC migration appears largely unaffected in germ-free mice ${ }^{66}$. Therefore, the exact molecular mechanisms controlling CCR7 expression and $\mathrm{CDC}$ migration in the steady state still require further investigation.

Unlike CDCs, monocyte-derived cells appear largely confined to the $L P$, fail to express CCR7, and do not migrate into intestinal lymph towards MLNs ${ }^{16,17,25,68}$. It is worth noting that, under inflammatory conditions, the number of $\mathrm{LN}$ monocyte-derived cells is increased, which may have functional consequences for $T$ cell priming. However, these monocyte-derived cells mainly enter the LNs through blood vessels and not via lymph ${ }^{69}$. Nevertheless, several reports have suggested that, in inflammation, a small proportion of monocytes infiltrating the intestinal LP may upregulate CCR7, migrate to $\mathrm{LNs}$ and contribute to $\mathrm{T}$ cell priming $^{70,71}$. One should be cautious when interpreting these data as the inflammatory monocytes have a surface phenotype highly reminiscent of the $\mathrm{CD} 103^{-} \mathrm{CDC2}$, including expression of intermediate levels of $\mathrm{CX}_{3} \mathrm{CR} 1^{17,72}$. In addition, CD64 has been shown to be expressed by a subset of lung $C D C 2 s$ under inflammatory conditions, making a distinction between $\mathrm{CD}_{103^{-}}$ CDC2 and monocyte-derived cells even more complex ${ }^{21}$. The use of additional phenotypic markers, such as MerTK, and, most definitively, of fate mapping experiments, single-cell RNAseq analyses, and direct transfers of potential progenitors will be necessary to fully elucidate the putative contribution of monocyte-derived cells to the pool of lymph-borne APCs in inflammation.

\section{Induction of tolerance}

The MLN chain comprises individual LNs, which are linked to lymphatic drainage in parallel, such that each MLN in the chain drains a particular part of the intestine ${ }^{18,73-75}$. Thus, LP CDCs from different gut segments migrate to distinct MLNs where they fulfill their most important function by presenting antigens to naïve $\mathrm{CD}^{+}$and $\mathrm{CD}^{+} \mathrm{T}$ cells and instructing their differentiation.

In the steady state, migration of CDCs from the intestinal LP primarily results in the presentation of "harmless" antigens to naïve $\mathrm{T}$ cells in the MLNs. Intestinal LP CDCs present these intestinal antigens in a tolerogenic manner, inducing the differentiation of naïve $\mathrm{CD}^{+}{ }^{+} \mathrm{T}$ cells into Foxp $^{+}$Tregs.

SI LP CDCs and migratory MLN CDCs express high levels of aldehyde dehydrogenase enzymes ${ }^{76,77}$. These enzymes catalyze the conversion of the Vitamin A metabolite retinal into retinoic 
44

acid (RA). Upon antigen presentation, RA signaling can instruct the naïve $T$ cells to differentiate into Foxp $3^{+}$Tregs (Fig. 1) ${ }^{76,77}$. Interestingly, aldehyde dehydrogenase-expressing gut CDCs also induce the upregulation of the gut homing factors CCR9 and the integrin $\alpha 4 \beta 7$ on the developing $T$ cells, in an RA-dependent manner $8,78,79$. The induction of gut-homing Tregs by SI LP CDCs may be one of the principal mechanisms by which the intestinal immune system maintains tolerance to food-derived antigens, socalled "oral tolerance" ${ }^{1}$. Indeed, genetic depletion of cDCs or the blockade of steady-state CDC migration to the MLNs leads to a failure of oral tolerance ${ }^{9,80}$. Interestingly, colonic LP CDCs have relatively low expression of aldehyde dehydrogenases, correlating with lower levels of RA in the colon LP and colon-draining MLNs ${ }^{74}$. This may suggest an anatomical basis for the segregation of CDC functional specialization, with proximal gut segments and associated LN drainage being more prone to tolerance induction whereas more distal sites may favor the induction of immunity. However, it is important to note that colonic migrating cDCs can induce $\mathrm{Foxp}^{+} \mathrm{T}$ cell responses and tolerance after intrarectal administration of soluble antigen ${ }^{81}$. It will be important to further elucidate the mechanisms that colonic CDCs use to induce tolerance and how these may differ from those used by cDCs in the SI LP. In addition, depending on their anatomical location, CDCs are exposed to different sources of antigen. Hence, SI LP CDCs may primarily be responsible for the processing and presentation of soluble dietary antigens whereas colonic LP CDCs may rather encounter higher levels of antigens derived from the intestinal microbiota.

In the steady state, LP CDCs in both the small intestine and colon have a range of adaptations that enable them to imprint a gut-homing and tolerogenic profile on developing $T$ cells. In addition to RA metabolism, LP CDCs can produce the tolerogenic cytokine TGF $\beta$ and express the $\operatorname{aV} \beta 8$ integrin that cleaves the inactive pro-TGF $\beta$ into its active form (Fig. 1). The deletion of the $\beta 8$ integrin on $\mathrm{CD}_{11 \mathrm{c}^{+}}$cells leads to a marked decrease in their ability to induce Foxp $3^{+}$Tregs $^{82}$. More recently, IL-33 deriving

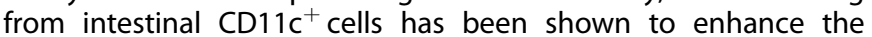
development of intestinal Foxp $3^{+} \mathrm{T}$ cells, which may represent another mechanism by which LP CDCs can induce tolerogenic responses and maintain gut homeostasis ${ }^{83}$. These adaptations of LP CDCs are thought to be the result of accumulated signals from the tissue microenvironment, sometimes referred to as tissue conditioning. Most notably, dietary and bile retinoids induce the expression of aldehyde dehydrogenase enzymes in $\mathrm{SI} \mathrm{CDCs}^{78,84}$. Moreover, blocking of $\mathrm{RA}^{85}$ or TGF $\beta$ signals ${ }^{41}$ in $\mathrm{CDCs}$ results in a decrease of the tolerogenic $\mathrm{CD} 103^{+} \mathrm{LP} \mathrm{CDC} 2 \mathrm{~s}$, indicating a role of these factors in the conditioning of LP CDC towards a tolerogenic phenotype. In addition, a variety of local factors can have a conditioning effect on intestinal $\mathrm{CDCs}$, including thymic stromal lymphopoietin (TSLP) production by epithelial cells ${ }^{86}$, aryl hydrocarbon receptor (AhR) ligands ${ }^{87}$, prostaglandin E2 ${ }^{88}$, and vasoactive intestinal peptide $(\mathrm{VIP})^{89}$. In the colonic mucosa, bacterial metabolites, such as short-chain fatty acids, can help maintain a tolerogenic LP CDC phenotype ${ }^{90}$. Finally, in addition to intestinederived signals, the MLN microenvironment may influence the tolerogenic function of migrating $\mathrm{CDCs}$, notably via RA production by the MLN stroma ${ }^{91,92}$.

It is not currently clear which LP CDC subset is primarily responsible for the maintenance of oral tolerance. $\mathrm{CDC} 1 \mathrm{~s}$ express higher levels of several tolerogenic factors, including aldehyde dehydrogenase and integrin $\beta 8$, than $C D C 2 s$. Moreover, despite having a normal number of intestinal Tregs, CDC1 deficient mice show a reduction in de novo differentiation of Foxp $3^{+}$Tregs from naïve $T$ cells in response to orally fed antigen ${ }^{80}$. In addition, one of the best-characterized roles of the CDC1 lineage is crosspresentation, the presentation of exogenous antigens on $\mathrm{MHCl}$, which is essential for the priming of $\mathrm{CD}^{+} \mathrm{T}$ cells ${ }^{93-95}$. Intestinal LP
CDC1s can take up enterocyte-expressed antigen and transport it via lymph to the MLN ${ }^{25,55}$. In the absence of inflammatory stimuli, CDC1s can cross-present this cellular cargo to cognate $\mathrm{CD}^{+} \mathrm{T}$ cells in the MLN and induce their differentiation into a regulatory $C D 8^{+}$ Foxp3 $^{+}$phenotype ${ }^{96}$.

However, it is important to note that both LP CDC1s and CDC2s are capable of inducing Foxp $3^{+}$Tregs. Notably, $\mathrm{CD}_{103^{+}} \mathrm{CD}_{11 \mathrm{~b}^{+}}$ cDC2s induce Foxp3 $3^{+}$Tregs more efficiently, while CD103 ${ }^{-} \mathrm{cDC} 2 \mathrm{~s}$ prime $T$ cells towards a more immunogenic phenotype ${ }^{16,17}$. In addition, while depletion of total intestinal CDCs results in a loss of intestinal Tregs, selective depletion of either $\mathrm{CDC} 1 \mathrm{~s}$ or the $\mathrm{CD} 103^{+}$ subset of $\mathrm{CDC} 2 \mathrm{~s}$ does not alter the number or frequency of Foxp $^{+}$Tregs in the SI or the induction of oral tolerance ${ }^{80,97}$. It is therefore likely that both major LP CDC subsets are capable of maintaining tolerogenic responses, perhaps specializing for different sources of antigen (Table 2$)^{25,98}$.

\section{Immunity and inflammation}

While LP cDCs promote tolerance to gut antigens in the steady state, in inflammation or upon direct stimulation they can adopt a more immunogenic phenotype, characterized by increased inflammatory cytokine production and induction of effector T cells (Table 2$)^{24,99,100}$. Indeed, LP CDCs retain functional plasticity and can be activated to produce Th1 and Th17 promoting cytokines, such as IL-12, IL-6, and IL-23, upon activation by TLR ligands, often in combination with other factors. For example, $\mathrm{CD}_{103^{+}} \mathrm{CDCs}$ in intestinal lymph respond to TLR2 stimulation by producing increased concentrations of IL-12 p40 and IL-6 ${ }^{101}$, and by priming IFN- $\gamma$ producing $\mathrm{CD} 4^{+}$and $\mathrm{CD} 8^{+} \mathrm{T}_{\text {cells }}{ }^{16}$. Similarly, LP CDCs can be activated by TLR3, TLR7, or TLR9 agonists ${ }^{24,63}$, while stimulation of $\mathrm{CDC} 2 \mathrm{~s}$ with the TLR5 ligand flagellin increases their cytokine production and induces the differentiation of IFN- $\gamma$ or IL17 producing effector $\mathrm{CD}^{+} \mathrm{T}^{\text {cells }}{ }^{100}$. Interestingly, CD103 ${ }^{-} \mathrm{LP}$ CDC2s show a higher basal level of IL-12 and IL-23 production compared to $\mathrm{CD}_{103^{+}} \mathrm{CDC} 2 \mathrm{~s}$ and can induce IFN- $\gamma$ or IL-17 producing $\mathrm{T}$ cells even without overt stimulation ${ }^{16,17}$. It is, therefore, possible that $\mathrm{CD}_{103^{-}} \mathrm{CDC2s}$ may represent a subset of intestinal CDCs that have not been fully conditioned by the intestinal environment and thus retain a largely immunogenic phenotype. The balance between the two subpopulations of $\mathrm{CDC} 2 \mathrm{~s}$ may thus contribute to the equilibrium between immunity and tolerance in the intestine.

Several lines of evidence point to the important role of LP CDC1s in the induction of Th1 responses (Fig. 1 and Table 2). IL-12 production by $\mathrm{CDC} 1 \mathrm{~s}$ is necessary for effective immune responses to Toxoplasma gondii infection ${ }^{102}$. Notably, intestinal Th1, but not Th17, cells are reduced in mice with a CD11c-targeted deletion of IRF8, which lack all cDC1s, both in steady state ${ }^{35}$ and in Tritichomonas musculis infection ${ }^{103}$.

In addition, cross-presentation by $\mathrm{CDC} 1$ is thought to be essential for the priming of cytotoxic $T$ lymphocyte (CTL) responses ${ }^{93-95}$. In vivo activation by the TLR7 agonist R848 increases the migration of $\mathrm{LP} C D C 1 \mathrm{~s}$ to the MLN where they crossprime $\mathrm{IFN}-\gamma^{+} \mathrm{CD}^{+}$effector $\mathrm{T}$ cells specific for enterocyteexpressed antigen ${ }^{25}$. However, optimal CTL responses in this model, as well as in rotavirus infection, are reduced, but not abolished in the absence of $\mathrm{CDC} 1 \mathrm{~s}$, indicating that other $\mathrm{CDC}$ subsets may contribute in certain contexts ${ }^{96,104}$.

In contrast, most data points to the importance of intestinal CDC2s in the induction of Th17 responses (Fig. 1 and Table 2). Multiple genetic models of gut CDC2 depletion exhibit reduced

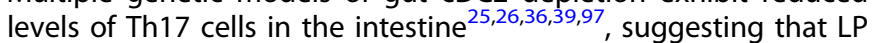
CDC2s play an important role in the priming of Th17 cells. Depletion of $\mathrm{CDC} 2 \mathrm{~s}$ correlates with reduced expansion of both IL17 and IFN- $\gamma$ producing $T$ cells in the context of experimental colitis $^{105}$, but also with amelioration of macrophage-induced inflammation in a mouse model of postoperative ileus ${ }^{106}$. In 
Table 2. Functions of intestinal dendritic cells.

\begin{tabular}{|c|c|c|c|}
\hline Tissue & Type & Subset & Functions \\
\hline \multirow{3}{*}{ 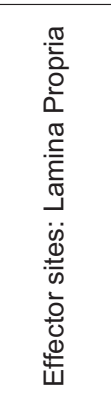 } & $\mathrm{cDC1}$ & CD103+ CD11b- & $\begin{array}{l}\text { Uptake, transport and Cross-presentation of IEC antigen } 25,55 \\
\text { Treg induction } 80,97 \\
\text { Th1 induction } 35,102103 \\
\text { Priming of IFN- } \gamma+\text { CD8+ effector T-cells }{ }^{25} \\
\text { Initiation of anti-rotavirus IgA responses }{ }^{116}\end{array}$ \\
\hline & \multirow{2}{*}{$\mathrm{cDC} 2$} & $\mathrm{CD}_{103^{+}} \mathrm{CD}_{11} \mathrm{~b}^{+}$ & $\begin{array}{l}\text { Treg induction } 16,17,80,97 \\
\text { Th2 induction (small intestine) }{ }^{112} \\
\text { Th17 cell induction } 17,26,36,39,97 \\
\text { Flagellin-dependent induction of mucosal IgA } 100,114,115\end{array}$ \\
\hline & & CD103- CD11 $b^{+}$ & $\begin{array}{l}\text { Th2 induction (colon) }{ }^{112} \\
\text { Th17 induction }{ }^{16,17} \\
\text { Induction of IFN-y or IL-17 producing T cells (small intestine) }{ }^{16,17}\end{array}$ \\
\hline \multirow{5}{*}{ 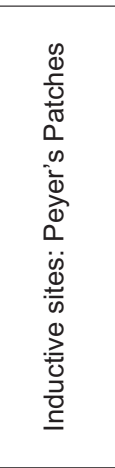 } & cDC1 & $\mathrm{SIRP} \alpha^{-} \mathrm{XCR} 1^{+}$ & $\begin{array}{l}\text { Naive helper T cells priming }{ }^{13} \\
T \text { cell polarization for IFN } \gamma \text { production }{ }^{13}\end{array}$ \\
\hline & \multirow[b]{2}{*}{ cDC2 } & Immature, $\mathrm{CCR}^{+} \mathrm{SIRP} \alpha^{+} \mathrm{CD} 11 \mathrm{~b}^{-}$ & Interaction with the FAE and LysoDC, antigen uptake ${ }^{10,137}$ \\
\hline & & Mature, $\mathrm{CCR} 7^{+} \mathrm{SIRP} \alpha^{+} \mathrm{CD} 11 \mathrm{~b}^{\mathrm{int}}$ & $\begin{array}{l}\text { Naive helper T cell priming }{ }^{11,13} \\
\text { IL-6 production and generation of Th17 cells }{ }^{146}\end{array}$ \\
\hline & \multirow[t]{2}{*}{ LysoDC } & $\begin{array}{l}\text { Subepithelial, BST2 } 2^{\text {int }} \text { MerTK }^{+} \mathrm{Emb}^{+} \mathrm{CD} 4^{-} \\
\mathrm{CX}_{3} \mathrm{CR}^{+} \text {Lysozyme }^{+}\end{array}$ & $\begin{array}{l}\text { Bacteria and particulate antigen uptake }{ }^{11,13,138-140} \\
\text { Innate defense of the SED }{ }^{13} \\
\text { Migration to the periphery of the IFR upon stimulation }{ }^{11} \\
\text { IL-6 and TNF production }{ }^{13} \\
\text { Naive helper T cell priming }{ }^{11,13} \\
\text { Induction of Th1 } 1^{13} \text { and Th17 cells }{ }^{146} \\
\text { Antigen cross-presentation and antigen-specific naive cytotoxic T cell priming }{ }^{147}\end{array}$ \\
\hline & & $\begin{array}{c}\text { Follicular, BST2 }{ }^{\text {int }} \text { MerTK }^{+} \text {Emb- CD4 }^{-} \\
\mathrm{CX}_{3} \mathrm{CR}^{+}{ }^{+} \text {Lysozyme }^{+}\end{array}$ & Unknown \\
\hline
\end{tabular}

addition to $\mathrm{CDC} 2 \mathrm{~s}$, monocyte-derived cells have been proposed to play a role in Th17 cell generation in response to specific microorganisms. Indeed, the Th17 responses to segmented filamentous bacteria in the small intestine ${ }^{107}$ and to Candida albicans in the colon ${ }^{108}$ do not require CDCs but monocytederived cells, suggesting that, in some contexts, these T cells may develop independently of the paradigm of $\mathrm{CDC}$ priming in lymphoid organs. Interestingly, while it has been suggested that the production of IL-23 by $\mathrm{CD} 103^{+} \mathrm{CDC} 2 \mathrm{~s}$ is indispensable for the elimination of Citrobacter rodentium ${ }^{38}$, complete ablation of this CDC population does not alter susceptibility to $C$. rodentium or Salmonella $s p$. infection ${ }^{97}$. Notably, IL-23 production by $\mathrm{CX}_{3} \mathrm{CR} 1^{+}$ phagocytes, which include both $\mathrm{CD}_{103^{-}} \mathrm{CDC} 2 \mathrm{~s}$ and monocytederived cells, is responsible for both the induction of IL-22 as well as the inhibition of deleterious $\mathrm{IL}-12$ production by $\mathrm{CDC} 1 \mathrm{~s}$ in $C$. rodentium infection ${ }^{109}$. While the exact identity of the IL-23 producing cells in C. rodentium infection is still uncertain, it is worth noting that $\mathrm{CD} 11 \mathrm{c}^{+}$but not $\mathrm{LysM}^{+}$cells produce IL-23 in response to MyD88 activation ${ }^{110}$.

The induction of Th2 responses in the gut is comparatively less well understood. Nevertheless, priming by CDCs is required as Th2 responses are completely abolished upon experimental depletion of $\mathrm{CDCs}^{111}$. The results from several different infection models point to the crucial role of $\mathrm{CDC} 2 \mathrm{~s}$ in the induction of Th2 responses ${ }^{112,113}$. Notably, the priming of Th2 responses to Schistosoma mansoni eggs appears to be controlled by different subpopulations of $\mathrm{CDC} 2 \mathrm{~s}$ in different tissues: $\mathrm{CD} 103^{+} \mathrm{CDC} 2 \mathrm{~s}$ in the small intestine but $\mathrm{CD}_{103^{-}} \mathrm{CDC} 2 \mathrm{~s}$ in the colon ${ }^{112}$.

In addition to their role in priming $T$ cell responses, LP and migratory MLN CDC subsets also aid the generation of mucosal antibody responses, notably secretory immunoglobulin $A(\operatorname{sg} A)$ (Fig. 1). Indeed, flagellin-dependent induction of slgA largely seems to depend on the activation of the IRF4-dependent, $\mathrm{CD}_{103^{+}} \mathrm{CD}_{11 \mathrm{~b}^{+}} \mathrm{CDC}$ subset $^{100,114,115}$. Conversely, CDC1s appear to have a crucial role in the initiation of anti-rotavirus slgA responses in the MLNs but are dispensable for the maintenance of homeostatic slgA levels, suggesting a context-dependent role for cDC subsets in slgA induction (Table 2$)^{116}$.

\section{DENDRITIC CELLS OF GUT-ASSOCIATED LYMPHOID TISSUES}

Mouse and human GALTs encompass PPs and large numbers of ILFs but also species-specific cecal and colonic patches in mice and appendix in humans (reviewed in refs. ${ }^{117,118}$ ). Mouse and human PP, cecal and colonic patches develop during embryogenesis and are clusters of $B$ cell follicles forming domes at the surface of the mucosa. By contrast, murine ILFs located both in the small intestine and colon develop postnatally under the combined influence of dietary products and microbiota ${ }^{119-121}$. Consequently, they are highly dynamic structures with many different sizes and maturation stages developing from small clusters of CCR6 ${ }^{+}$type 3 innate lymphoid cells (ILC3s) termed cryptopatches and giving rise to $B$ cell follicles containing germinal centers (GCs) in mature $\mathrm{ILFs}^{122,123}$. Interestingly, in absence of murine ILFs the composition of the microbiota is altered, demonstrating a reciprocal regulation of the microbiota by ILFs ${ }^{119}$. In PP, each dome is separated from the others by dome-associated villi (DAV) beneath which lie the IFRs enriched in naïve T cells ${ }^{119-121}$. Murine mature ILFs strikingly resemble a single dome of PP without the organized T cell zone of the IFRs. By contrast, human ILFs contain a T cell area surrounding the $B$ cell follicle ${ }^{124}$. The follicle-associated epithelium (FAE) of both human and murine ILFs and PPs contains specific cells termed $M$ cells that are specialized in the transport of antigens from the lumen to the underlying subepithelial dome (SED). Like PPs, ILFs are inductive sites for the generation of IgA-secreting cells ${ }^{119}$. Whereas in murine ILFs, IgA-secreting cells are thought to be mainly generated by a $T$ cell-independent pathway ${ }^{125}$, the existence of a $T$ cell area and of putative follicular helper $T$ cells (Tfh) suggests a T cell-dependent pathway in human ILFs ${ }^{124}$. So far, GALT-associated DCs have been mainly studied in PP and small intestine cryptopatches and ILFs of mice and only these will be discussed below. 


\section{Specificity of ILF CDCs}

Although observed long ago ${ }^{126,127}, \mathrm{CD} 1 \mathrm{c}^{+}$phagocytes of small intestine ILFs and cryptopatches have only been characterized recently. They are mainly made up of a unique $C D 103^{-} \mathrm{CD} 11 \mathrm{~b}^{+}$ CDC2 subset defined by its expression of lysozyme M, PLET1, and of the IL-22 binding protein (IL22-BP), a soluble receptor of IL-22 that neutralizes its activity ${ }^{128}$. Interaction between the lymphotoxin (LT) a1 $\beta 2$ produced by ILF and cryptopatch-specific CCR6 ${ }^{+}$ ILC3s and the LT $\beta$ receptor (LT $\beta R$ ) expressed by newly recruited $\mathrm{CDC} 2 \mathrm{~s}$ drive the differentiation of the latter into cryptopatch and ILF-specific cDC2s. Interestingly, CCR6 ${ }^{+}$ILC3s secrete a large amount of IL-22 that could be fine-tuned locally by cryptopatch and ILF CDC2 production of IL22-BP ${ }^{128}$. Through inhibition of IL-22 signaling, IL22-BP could play a role in lipid absorption by promoting free fatty acid transporter expression by enterocytes ${ }^{128}$. Moreover, the IL-22BP blockade of IL-22 is known to facilitate access of antigens to the PP FAE and their internalization by $M$ cells $^{129}$. Therefore, similar functions could be assigned to IL-22BP in ILFs, allowing an efficient uptake of local luminal antigens by $M$ cells and the initiation of adaptive immune responses by ILFspecific $C D C 2 s$ that could contribute to microbiota modulation. It remains to be determined whether specific $\mathrm{CDC1}$ populations or monocyte-derived cells with DC functional properties, such as those in PP, play also a role in the ILF-mediated adaptive immune responses.

\section{Phenotype, location, and specificity of CDCs in Peyer's patches} Both $\mathrm{CDC} 1 \mathrm{~s}$ and $\mathrm{CDC} 2 \mathrm{~s}$ are present in PPs but with a $\mathrm{CDC} 2$ prevalence and distinct locations for each subset (Fig. 1). Whereas $\mathrm{CDC} 1 \mathrm{~s}$ are mainly concentrated in the IFRs ${ }^{23}, \mathrm{CDC} 2 \mathrm{~s}$ are present both in the SED and in the IFRs depending on their maturation state $^{10}$. Indeed, PP CDC2s display a continuum of differentiation states ranging from immature $\mathrm{CDC} 2 \mathrm{~s}$ that express CCR6, low levels of surface $\mathrm{MHCll}$ and no $\mathrm{CD} 11 \mathrm{~b}$ to fully mature $\mathrm{CDC} 2 \mathrm{~s}$ that express CCR7, high levels of surface MHCIl, and intermediate levels of CD11b. Accordingly, immature $\mathrm{CDC} 2 \mathrm{~s}$ are mainly located in the SED where CCL20, the ligand for CCR6, is secreted by the FAE whereas fully mature $\mathrm{CDC} 2 \mathrm{~s}$ are mainly located in the IFR, where CCL19 and CCL21, the ligands of CCR7 are expressed ${ }^{10}$. Therefore, immature and mature $\mathrm{CDC2}$ are ideally located to acquire luminal antigens and present antigens to interfollicular naive $T$ cells, respectively. SED and IFR CDC2s in all their different flavors differ phenotypically from DAV and conventional villus $\mathrm{CDC} 2 \mathrm{~s}$ at least by their consistent lack of CD101 expression and their lower expression of CD11b (Table 1). Therefore, caution must be taken when using $C D 11 \mathrm{~b}$ as a marker of PP $C D C 2 s$, especially by microscopy for which CD11b expression in PP $C D C 2 s$ is too low as compared to that of LysoDCs and DAV CDC2s to be detected ${ }^{10}$.

Interestingly, like ILF $\mathrm{CDC} 2 \mathrm{~s}$, half of $\mathrm{CD} 11 \mathrm{~b}^{+} \mathrm{CDC} 2 \mathrm{~s}$ express lysozyme $M^{10}$. Moreover, II22ra2, the gene encoding IL-22BP, is expressed by $\mathrm{CD}_{11} \mathrm{~b}^{+} \mathrm{CDC2s}$ although at lower levels than in monocyte-derived cells ${ }^{6}$. Finally, the homeostasis of LTßRexpressing $C D C 2 s$ depends on signaling by $L T a 1 \beta 2$, which is produced by ILC3s ${ }^{130}$. Therefore, like in ILFs, an imprinting of CDC2s by ILC3s that leads to lysozyme M and IL22-BP expression is likely to occur in PPs. Unlike $C D C 2 s$, up to now, no specific expression profile has been ascribed for CDC1 in PPs or ILFs as compared to other tissues.

\section{Specificity of the PP specialized monocyte-derived LysoDCs}

In PP, monocytes give rise not only to macrophages but also to the specialized lysozyme-expressing DCs termed LysoDCs ${ }^{13}$. LysoDCs are a hallmark of the SED where, together with macrophages, they represent the main phagocyte subset (Fig. 1). LysoDCs are also scattered through the follicle but are virtually absent from the IFR at a steady state. Unlike most monocytederived cells from peripheral tissues, LysoDCs but also PP macrophages do not express CD64, F4/80, CD14, and many other classic macrophage markers (Table 1$)^{15}$. However, both retain strong expression of $\mathrm{CX}_{3} \mathrm{CR} 1$ and MerTK. Unexpectedly, both also express the classic pDC marker, BST2, which has led to confusion in the past. Unlike neighboring macrophages, LysoDCs express high levels of MHCII but no CD4 (Table 1), have a short lifespan and their recruitment strongly depends on CCR2, the chemokine receptor that allows monocyte egress from the bone marrow ${ }^{13}$. Recruitment of LysoDC in the SED may also depend on DOCK8 expression $^{131}$, a guanine exchange factor for $\mathrm{Cdc} 42$ required for interstitial migration of $\mathrm{CDC}_{2} \mathrm{~s}^{132-134}$. Immature LysoDCs can proliferate in situ before differentiating either into subepithelial mature LysoDCs in close contact with the FAE or into follicular LysoDCs that lack the typical DC gene signature acquired by the former ${ }^{11}$. All LysoDCs except follicular ones express embigin but only subepithelial mature ones express CD24 and PLET1. Based on conserved maturation marker expression, a similar differentiation process is likely to occur in humans ${ }^{11}$.

\section{Functions of Peyer's patch LysoDCs and CDCs}

Antigen sampling. Whereas villi, specialized for nutrient absorption, are well protected by physical (mucus, glycocalyx, and tight junctions), chemical (antimicrobial peptides), and immune (slgAs) barriers from penetration of pathogens, PPs are sentinel sites dedicated to their detection. Accordingly, PPs are selectively exposed to particulate antigens and pathogens through the permissive microenvironment of the FAE. For instance, the FAE lacks goblet cells and polymeric IgA receptor expression and, therefore, does not secrete mucus and slgAs, respectively ${ }^{135,136}$. Some of these FAE permissive characteristics, such as lack of antimicrobial protein secretion and altered surface glycosylation, rely on IL-22 signaling inhibition by IL-22BP produced mainly by LysoDCs and subepithelial macrophages but also to a lesser extent by $C D C 2 s$, like in ILFs ${ }^{6,128,129}$. In addition, subepithelial phagocytes but also ILC3s produce S100A4, a key protein for the maturation of $M$ cells necessary for the efficient transcytosis of luminal antigens to the SED ${ }^{131}$. Moreover, LysoDCs and CDC2s have privileged interactions with $M$ cells, as illustrated by their ability to extend dendrites through $M$ cell-specific transcellular pores or to reside together with $B$ and helper T cells in a basolateral invagination of

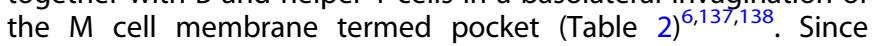
LysoDCs outnumber $C D C 2 s$ in the SED but also are more efficient than them in phagocytosing particulate antigens ${ }^{10,11,13,139}$, it is however unlikely that CDC2s play a major role in pathogen uptake. Indeed, both Salmonella Typhimurium and Listeria monocytogenes are mainly taken up by LysoDCs and/or subepithelial macrophages but not by $\mathrm{CDC} 2 \mathrm{~s}^{139,140}$. In addition, other particulate materials have been shown to be selectively engulfed by LysoDCs and subepithelial macrophages but not $\mathrm{CDC} 2 \mathrm{~s}$, including microspheres, adenoviral vectors, IgA-opsonized antigens, $M$ cellreleased subepithelial vesicles, and dying $M$ cells ${ }^{13,139,141-143}$. All differentiation states of LysoDCs are equally able to internalize particulate antigens in vitro but mature LysoDCs are the most susceptible to encounter antigens in vivo due to their proximity to the epithelium ${ }^{11}$. Although LysoDCs are the main phagocytes extending dendrites into the gut lumen, subepithelial macrophages show the same efficiency in internalizing particulate antigens in vivo ${ }^{13}$, strongly suggesting that the main path of sampling is mediated by $M$ cell transcytosis at a steady state (Fig. 1). The contribution of $\mathrm{CDC} 2 \mathrm{~s}$ in antigen uptake remains to be explored but could be related to soluble rather than particulate antigen sampling and/or, as demonstrated in the $\mathrm{LP}^{54}$, to antigen acquisition by transfer from LysoDC and subepithelial macrophages with which they strongly interact in the SED and $F A E^{10}$. In any case, the different mechanisms of luminal antigen uptake (transcytosis, transcellular dendrites, and vesicle release in the subepithelial extracellular milieu) strictly rely upstream on $M$ cells and lack of $M$ cells prevents most sampling events and the initiation of the subsequent $\lg A$ immune response ${ }^{144,145}$. 
Innate defense mechanisms. Whereas access to the FAE is facilitated, the SED represents a hostile environment for pathogens. Subepithelial phagocytes are indeed fully equipped to fight invading pathogens. This is highlighted by LysoDCs' and subepithelial macrophages' unrivaled expression of the antibacterial enzyme lysozyme in several species including humans ${ }^{11,139}$. These monocyte-derived cells also display strong antimicrobial gene signatures as compared to $\mathrm{CDCs}$, indicating that they are the main actors in PP innate defense (Table 2$)^{13}$. Thus, genes involved in antiviral, antibacterial, and antifungal defense pathways, including large panels of molecular pattern sensors (TLRs, C-type lectin receptors, NAIPs, STING, ZBP1, and RIG-I), NLRC4 inflammasome formation, bacterial and viral replication inhibition, metal sequestration, and detoxification mechanisms are upregulated in monocyte-derived cells. Interestingly, the latter also promote innate defense mechanisms at distant sites, i.e., in villi. Thus, upon engulfment of the enteropathogenic bacteria, Listeria monocytogenes PP monocyte-derived cells produce IL-23 and IL-12, which induce the production of IL-22 and IL-17 or IFN- $\gamma$, respectively ${ }^{140}$. In turn, IL-17 causes pericryptal stromal cells to produce IL-11, which, in conjunction with IL-22 produced by ILC3s, activates STAT3. In parallel, IFN- $\gamma$ activates STAT1. Finally, both transcriptional factors lead to accelerated intestinal epithelium renewal and a decreased number of mature goblet cells expressing accessible E-cadherin, the receptor for Listeria invasion protein Internalin A, thereby protecting villi from further infection. Detection of microbiota species by Mincle/Clec4e, which is mainly expressed by LysoDCs and macrophages, also promotes IL-23 production by these phagocytes, followed by activation of ILC3s leading to IL-22 production, barrier integrity strengthening, and microbial translocation limitation ${ }^{146}$.

Migration. In steady state, following their sampling activity, CDC2s mature, lose CCR6 while gaining CCR7 expression, and continually migrate from the SED to the IFRs in an unsynchronized way, but these mature CDC2s never display a fully activated profile ${ }^{10}$. However, upon stimulation of PP with the TLR7 ligand, R848, the indirect activation of subepithelial CDC2s by TNF rapidly leads to their synchronized activation, CCR7 expression, and migration in the IFRs ${ }^{11}$. In parallel, DAV $\mathrm{CDC} 2 \mathrm{~s}$ also migrate into the IFRs ${ }^{10}$, unlike conventional villus $C D C 2 s$ that migrate to the $\mathrm{MLNs}^{62}$. Interestingly, LysoDCs, which, unlike CDC2s, express TLR7 and can be directly activated by TLR7 ligands, also acquire CCR7 but much later than $\mathrm{CDC} 2 \mathrm{~s}$, and their positioning following migration is more at the IFR periphery than $\mathrm{CDC} 2 \mathrm{~s}$ (Fig. 1) ${ }^{11}$. Nevertheless, this location at the border between the B and the T cell zone coincides with the area of high proliferation observed after stimulation, suggesting that LysoDCs could play a role in the stimulation of both $T$ and $B$ cells.

$T$ cell priming. PP $\mathrm{CDC} 1 \mathrm{~s}$ and $\mathrm{CDC} 2 \mathrm{~s}$ and fully mature LysoDCs, but not macrophages, are able to induce naïve $\mathrm{CD}^{+}{ }^{+} \mathrm{T}$ cell proliferation in vitro (Table 2$)^{11,13}$. Both $\mathrm{CDC} 1 \mathrm{~s}$ and LysoDCs prime naïve antigen-specific $\mathrm{CD}^{+}{ }^{+}$T cells for IFNy production while both $\mathrm{CDC} 2 \mathrm{~s}$ and LysoDCs promote T helper cell production of IL- $6^{13}$. In addition, detection of some microbiota species by Mincle/Clec4e expressed on LysoDCs and CDC2s fosters their IL-6 production and their ability to generate Th17 cells, thereby promoting the production of IL-17 and IL-22 that contribute to intestinal barrier integrity $^{146}$. Very recently, a LysoDC subset that expresses the complement fragment $\mathrm{C} 5 \mathrm{a}$ receptor, $\mathrm{CD} 88$, was shown to crosspresent antigens and prime antigen-specific naïve $\mathrm{CD}^{+} \mathrm{T}$ cells when stimulated by $\mathrm{C}^{147}$. Indeed, $\mathrm{C} 5 \mathrm{a}$ signaling in LysoDCs induces the recruitment of NOX2 to the phagosomes, reactive oxygen species production, lysosomal $\mathrm{pH}$ neutralization, translocation of antigens into the cytosol, and formation of $\mathrm{MHCl}$-antigen complexes for antigen cross-presentation. Moreover, in vivo infection with Listeria monocytogenes induces $\mathrm{C} 5 \mathrm{a}$ production by the stromal cell network of the SED where LysoDCs reside, suggesting that they could be activated for $\mathrm{T}$ cell cross-priming with Listeria antigens. However, the role of LysoDC in the generation of cytotoxic T cells against enteropathogenic bacteria in vivo still needs confirmation.

Unlike subepithelial $c D C 2 s$ that migrate continuously to the IFR, mature LysoDCs reside in the SED, making their encounter with naïve $T$ cells mainly located in the IFRs unlikely at steady state. Based on their pro-inflammatory profile, lack of LysoDC migration to the IFR at steady state could prevent an inflammatory response to the innocuous antigens they continuously sample, especially microbiota species. However, stimulation of PP can lead to their migration to the periphery of the IFR fostering strong interaction with naïve $T$ cells that may induce priming (Fig. 1) ${ }^{11}$. Indeed, among $T$ cells strongly interacting with LysoDCs, some display the features of newly activated and proliferating T cells. Nevertheless, in steady state, given the lack of LysoDCs in the IFRs and the lack of $\mathrm{CDC1}$ s in the SED, only migratory CDC2 may be able to present luminal antigens to interfollicular naïve $T$ cells and likely promote their differentiation into antigen-specific Tfh, in line with recent reports supporting the role of $\mathrm{CDC} 2$ in Tfh cell generation in other lymphoid organs ${ }^{133,148}$. These Tfh are essential for germinal center formation and generation of antigen-specific high-affinity slgAproducing cells.

IgA-secreting cell generation. PPs are the primary sites for the generation of $\mathrm{T}$ cell-dependent antigen-specific slgA-producing cells in the small intestine. IgA class switching can already occur in the SED before the migration of $B$ cells to the germinal center ${ }^{130}$. This requires the interaction between subepithelial $\mathrm{CCR}^{+} \mathrm{B}$ cells and lymphotoxin-dependent phagocytes expressing CD11C, $\mathrm{MHCll}$, and $\mathrm{CD} 11 \mathrm{~b}$. As this phenotype may correspond to any type of phagocytes present in the SED, i.e., LysoDCs, macrophages, and $C D C 2 s^{6}$, future studies will be necessary to clarify the identity of the phagocytes interacting with subepithelial B cells. Expression of the integrin $a v \beta 8$ by these phagocytes may be required for TGF $\beta$ activation and induction of IgA class switching ${ }^{130}$, although a recent study using an Itgb8-specific fluorescent reporter mouse, qRT-PCR and RNAseq analysis failed to detect the integrin $\beta 8$ on $\mathrm{CDC2}$ or monocyte-derived cells in $\mathrm{PP}^{116}$. In summary, the mechanisms leading to IgA class switching in the SED are just starting to be deciphered and their elucidation will require further investigation.

\section{CONCLUSION}

Research over the past 30 years has highlighted the importance of intestinal CDCs in the initiation of tolerance, the maintenance of physiological homeostasis to the microbiota as well as the induction of protective immune responses against pathogens. However, we are only now starting to unravel the relative contributions of the different subsets of $C D C s$ as well as those of cDCs present within the different compartments of the small and large intestine and their associated lymphoid tissues. Recent work has indeed shown that the gut immune response is highly compartmentalized providing targeted and adapted immune responses to the different regions of the gut based on the sensing of local luminal contents. This process is driven by different accessibility of antigens to the intestinal mucosa, several mechanisms of sampling, and various types and location of immune inductive sites. In addition, the ability of cDCs to induce either tolerogenic or immunogenic responses may rely on the type of antigens they encounter and how they are recognized as innocuous or harmful, but also on the location of their antigen sampling activity and how that location has conferred specific functional properties on them. For instance, it is now clear that LP cDCs of the small intestine and colon exists in different microenvironments, encounter different antigens and innate 
stimuli, and consequently have distinct functional properties. Moreover, similarly to how intestinal macrophages display an antiinflammatory profile in the gut LP but pro-inflammatory properties in PPs, a specific imprinting of CDCs and monocyte-derived phagocytes has begun to be appreciated in PPs and ILFs, although its full complexity remains to be explored. Accordingly, imprinting of cDCs but also LysoDCs by their microenvironment may influence the outcome of the immune response and allow distinct adaptive responses to be generated according to the sampling site, which may act to prevent excessive inflammation in effector sites but protect against infections and dysbiosis at immune inductive sites. Therefore, further research will be necessary to fully understand how the functionally distinct subsets of intestinal CDCs located at distinct sites orchestrate immune responses to particular pathogens or inflammatory disorders. Precise characterization of the functional plasticity of these cell populations will allow more accurate targeting of specific functional modules with a wide range of therapeutic applications-such as the induction of effective immunity in vaccination, fine-tuning of immune responses to the microbiota, and prevention of inflammatory diseases and allergy.

\section{REFERENCES}

1. Pabst, O. \& Mowat, A. M. Oral tolerance to food protein. Mucosal Immunol. 5, 232-239 (2012).

2. Hooper, L. V., Littman, D. R. \& Macpherson, A. J. Interactions between the microbiota and the immune system. Science 336, 1268-1273 (2012).

3. Guilliams, M. et al. Dendritic cells, monocytes and macrophages: a unified nomenclature based on ontogeny. Nat. Rev. Immunol. 14, 571-578 (2014).

4. Dress, R. J. et al. Plasmacytoid dendritic cells develop from $\operatorname{Ly} 6 \mathrm{D}(+)$ lymphoid progenitors distinct from the myeloid lineage. Nat. Immunol. 20, 852-864 (2019).

5. Yrlid, U. et al. Plasmacytoid dendritic cells do not migrate in intestinal or hepatic lymph. J. Immunol. 177, 6115-6121 (2006).

6. Da Silva, C., Wagner, C., Bonnardel, J., Gorvel, J. P. \& Lelouard, H. The Peyer's patch mononuclear phagocyte system at steady state and during infection. Front. Immunol. 8, 1254 (2017).

7. Bekiaris, V., Persson, E. K. \& Agace, W. W. Intestinal dendritic cells in the regulation of mucosal immunity. Immunol. Rev. 260, 86-101 (2014).

8. Johansson-Lindbom, B. et al. Functional specialization of gut CD103+ dendritic cells in the regulation of tissue-selective T cell homing. J. Exp. Med. 202, 1063-1073 (2005).

9. Worbs, T. et al. Oral tolerance originates in the intestinal immune system and relies on antigen carriage by dendritic cells. J. Exp. Med. 203, 519-527 (2006).

10. Bonnardel, J. et al. Distribution, location, and transcriptional profile of Peyer's patch conventional DC subsets at steady state and under TLR7 ligand stimulation. Mucosal Immunol. 10, 1412-1430 (2017).

11. Wagner, C. et al. Differentiation paths of Peyer's patch LysoDCs are linked to sampling site positioning, migration, and T cell priming. Cell Rep. 31, 107479 (2020).

12. Mowat, A. M. To respond or not to respond - a personal perspective of intestinal tolerance. Nat. Rev. Immunol. 18, 405-415 (2018).

13. Bonnardel, J. et al. Innate and adaptive immune functions of peyer's patch monocyte-derived cells. Cell Rep. 11, 770-784 (2015).

14. Cerovic, V., Bain, C. C., Mowat, A. M. \& Milling, S. W. Intestinal macrophages and dendritic cells: what's the difference? Trends Immunol. 35, 270-277 (2014).

15. Wagner, C. et al. Some news from the unknown soldier, the Peyer's patch macrophage. Cell Immunol. 330, 159-167 (2018).

16. Cerovic, V. et al. Intestinal CD103(-) dendritic cells migrate in lymph and prime effector T cells. Mucosal Immunol. 6, 104-113 (2013).

17. Scott, C. L. et al. CCR2(+)CD103(-) intestinal dendritic cells develop from DCcommitted precursors and induce interleukin- 17 production by T cells. Mucosal Immunol. 8, 327-339 (2015).

18. Houston, S. A. et al. The lymph nodes draining the small intestine and colon are anatomically separate and immunologically distinct. Mucosal Immunol. 9, 468-478 (2016).

19. Tamoutounour, S. et al. CD64 distinguishes macrophages from dendritic cells in the gut and reveals the Th1-inducing role of mesenteric lymph node macrophages during colitis. Eur. J. Immunol. 42, 3150-3166 (2012).

20. Huang, H. I. et al. Th17 immunity in the colon is controlled by two novel subsets of colon-specific mononuclear phagocytes. Front. Immunol. 12, 661290 (2021).

21. Bosteels, C. et al. Inflammatory type 2 CDCs acquire features of CDC1s and macrophages to orchestrate immunity to respiratory virus infection. Immunity 52, 1039-1056 e1039 (2020).
22. Guilliams, M. et al. Unsupervised high-dimensional analysis aligns dendritic cells across tissues and species. Immunity 45, 669-684 (2016).

23. Becker, M. et al. Ontogenic, phenotypic, and functional characterization of XCR1 $(+)$ dendritic cells leads to a consistent classification of intestinal dendritic cells based on the expression of XCR1 and SIRPalpha. Front. Immunol. 5, 326 (2014).

24. Fujimoto, K. et al. A new subset of CD103+CD8alpha+ dendritic cells in the small intestine expresses TLR3, TLR7, and TLR9 and induces Th1 response and CTL activity. J. Immunol. 186, 6287-6295 (2011).

25. Cerovic, V. et al. Lymph-borne CD8alpha+ dendritic cells are uniquely able to cross-prime CD8 + T cells with antigen acquired from intestinal epithelial cells. Mucosal Immunol. 8, 38-48 (2015).

26. Persson, E. K. et al. IRF4 transcription-factor-dependent CD103(+)CD11b(+) dendritic cells drive mucosal T helper 17 cell differentiation. Immunity 38, 958-969 (2013).

27. Watchmaker, P. B. et al. Comparative transcriptional and functional profiling defines conserved programs of intestinal DC differentiation in humans and mice. Nat. Immunol. 15, 98-108 (2014).

28. Sichien, D., Lambrecht, B. N., Guilliams, M. \& Scott, C. L. Development of conventional dendritic cells: from common bone marrow progenitors to multiple subsets in peripheral tissues. Mucosal Immunol. 10, 831-844 (2017).

29. Bogunovic, M. et al. Origin of the lamina propria dendritic cell network. Immunity 31, 513-525 (2009).

30. Varol, C. et al. Intestinal lamina propria dendritic cell subsets have different origin and functions. Immunity 31, 502-512 (2009).

31. Satpathy, A. T. et al. Zbtb46 expression distinguishes classical dendritic cells and their committed progenitors from other immune lineages. J. Exp. Med. 209, 1135-1152 (2012).

32. Kinnebrew, M. A. et al. Interleukin 23 production by intestinal CD103(+)CD11b $(+)$ dendritic cells in response to bacterial flagellin enhances mucosal innate immune defense. Immunity 36, 276-287 (2012).

33. Zeng, R. et al. Retinoic acid regulates the development of a gut-homing precursor for intestinal dendritic cells. Mucosal Immunol. 6, 847-856 (2013).

34. Edelson, B. T. et al. Peripheral CD103+ dendritic cells form a unified subset developmentally related to CD8alpha+ conventional dendritic cells. J. Exp. Med. 207, 823-36 (2010).

35. Luda, K. M. et al. IRF8 transcription-factor-dependent classical dendritic cells are essential for intestinal T cell homeostasis. Immunity 44, 860-874 (2016).

36. Schlitzer, A. et al. IRF4 transcription factor-dependent CD11b+ dendritic cells in human and mouse control mucosal IL-17 cytokine responses. Immunity 38, 970-983 (2013).

37. Tussiwand, R. et al. KIf4 expression in conventional dendritic cells is required for T helper 2 cell responses. Immunity 42, 916-928 (2015).

38. Satpathy, A. T. et al. Notch2-dependent classical dendritic cells orchestrate intestinal immunity to attaching-and-effacing bacterial pathogens. Nat. Immunol. 14, 937-948 (2013).

39. Lewis, K. L. et al. Notch2 receptor signaling controls functional differentiation of dendritic cells in the spleen and intestine. Immunity 35, 780-791 (2011).

40. Greter, M. et al. GM-CSF controls nonlymphoid tissue dendritic cell homeostasis but is dispensable for the differentiation of inflammatory dendritic cells. Immunity 36, 1031-1046 (2012).

41. Bain, C. C. et al. TGFbetaR signalling controls CD103(+)CD11b(+) dendritic cell development in the intestine. Nat. Commun. 8, 620 (2017).

42. Tenno, M. et al. Essential functions of Runx/Cbfbeta in gut conventional dendritic cells for priming Rorgammat(+) T cells. Life Sci. Alliance 3, e201900441 (2020).

43. Liu, Z. et al. Fate mapping via Ms4a3-expression history traces monocytederived cells. Cell 178, 1509-1525 e1519 (2019).

44. Bain, C. C. et al. Constant replenishment from circulating monocytes maintains the macrophage pool in the intestine of adult mice. Nat. Immunol. 15, 929-937 (2014).

45. Knoop, K. A., Miller, M. J. \& Newberry, R. D. Transepithelial antigen delivery in the small intestine: different paths, different outcomes. Curr. Opin. Gastroenterol. 29, 112-118 (2013).

46. Jang, $M$. H. et al. Intestinal villous $M$ cells: an antigen entry site in the mucosal epithelium. Proc. Natl Acad. Sci. USA 101, 6110-6115 (2004).

47. Kulkarni, D. H. et al. Goblet cell associated antigen passages support the induction and maintenance of oral tolerance. Mucosal Immunol. 13, 271-282 (2020).

48. Kulkarni, D. H. et al. Goblet cell associated antigen passages are inhibited during Salmonella typhimurium infection to prevent pathogen dissemination and limit responses to dietary antigens. Mucosal Immunol. 11, 1103-1113 (2018).

49. McDole, J. R. et al. Goblet cells deliver luminal antigen to CD103+ dendritic cells in the small intestine. Nature 483, 345-349 (2012).

50. Knoop, K. A. et al. Microbial antigen encounter during a preweaning interval is critical for tolerance to gut bacteria. Sci. Immunol. 2, eaao1314 (2017). 
51. Knoop, K. A., McDonald, K. G., McCrate, S., McDole, J. R. \& Newberry, R. D. Microbial sensing by goblet cells controls immune surveillance of luminal antigens in the colon. Mucosal Immunol. 8, 198-210 (2015).

52. Farache, J. et al. Luminal bacteria recruit CD103+ dendritic cells into the intestinal epithelium to sample bacterial antigens for presentation. Immunity $\mathbf{3 8}$, 581-595 (2013)

53. Niess, J. H. et al. CX3CR1-mediated dendritic cell access to the intestinal lumen and bacterial clearance. Science 307, 254-258 (2005).

54. Mazzini, E., Massimiliano, L., Penna, G. \& Rescigno, M. Oral tolerance can be established via gap junction transfer of fed antigens from $\mathrm{CX} 3 \mathrm{CR} 1(+)$ macrophages to CD103(+) dendritic cells. Immunity 40, 248-261 (2014).

55. Huang, F. P. et al. A discrete subpopulation of dendritic cells transports apoptotic intestinal epithelial cells to T cell areas of mesenteric lymph nodes. J. Exp. Med. 191, 435-444 (2000).

56. Itano, A. A. et al. Distinct dendritic cell populations sequentially present antigen to CD4 T cells and stimulate different aspects of cell-mediated immunity. Immunity 19, 47-57 (2003).

57. Ohl, L. et al. CCR7 governs skin dendritic cell migration under inflammatory and steady-state conditions. Immunity 21, 279-288 (2004).

58. Jang, M. H. et al. CCR7 is critically important for migration of dendritic cells in intestinal lamina propria to mesenteric lymph nodes. J. Immunol. 176, 803-810 (2006).

59. Ansel, K. M. et al. A chemokine-driven positive feedback loop organizes lymphoid follicles. Nature 406, 309-314 (2000).

60. Braun, A. et al. Afferent lymph-derived T cells and DCs use different chemokine receptor CCR7-dependent routes for entry into the lymph node and intranodal migration. Nat. Immunol. 12, 879-887 (2011).

61. Yrlid, U. A distinct subset of intestinal dendritic cells responds selectively to oral TLR7/8 stimulation. Eur. J. Immunol. 36, 2639-2648 (2006).

62. Yrlid, U. et al. Regulation of intestinal dendritic cell migration and activation by plasmacytoid dendritic cells, TNF-alpha and type 1 IFNs after feeding a TLR7/8 ligand. J. Immunol. 176, 5205-5212 (2006).

63. Garcias Lopez, A. et al. Migration of murine intestinal dendritic cell subsets upon intrinsic and extrinsic TLR3 stimulation. Eur. J. Immunol. 50, 1525-1536 (2020).

64. Wendland, M. et al. CCR9 is a homing receptor for plasmacytoid dendritic cells to the small intestine. Proc. Natl Acad. Sci. USA 104, 6347-6352 (2007).

65. Pugh, C. W. \& MacPherson, G. G. Non-lymphoid cells from rat intestinal lymph Adv. Exp. Med Biol. 149, 781-789 (1982).

66. Hagerbrand, K., Westlund, J., Yrlid, U., Agace, W. \& Johansson-Lindbom, B. MyD88 signaling regulates steady-state migration of intestinal CD103+ dendritic cells independently of TNF-alpha and the gut microbiota. J. Immunol. 195, 2888-2899 (2015).

67. Baratin, M. et al. Homeostatic NF-kappaB signaling in steady-state migratory dendritic cells regulates immune homeostasis and tolerance. Immunity $\mathbf{4 2}$, 627-639 (2015).

68. Schulz, O. et al. Intestinal CD103+, but not CX3CR1+, antigen sampling cells migrate in lymph and serve classical dendritic cell functions. J. Exp. Med. 206, 3101-3114 (2009)

69. Leal, J. M. et al. Innate cell microenvironments in lymph nodes shape the generation of T cell responses during type I inflammation. Sci. Immunol. 6, eabb9435 (2021).

70. Diehl, G. E. et al. Microbiota restricts trafficking of bacteria to mesenteric lymph nodes by CX(3)CR1(hi) cells. Nature 494, 116-120 (2013).

71. Zigmond, E. et al. Ly6C hi monocytes in the inflamed colon give rise to proinflammatory effector cells and migratory antigen-presenting cells. Immunity 37 1076-1090 (2012)

72. Bravo-Blas, A. et al. Salmonella enterica Serovar Typhimurium travels to mesenteric lymph nodes both with host cells and autonomously. J. Immunol. 202, 260-267 (2019).

73. Carter, P. B. \& Collins, F. M. The route of enteric infection in normal mice. J. Exp. Med. 139, 1189-1203 (1974).

74. Esterhazy, D. et al. Compartmentalized gut lymph node drainage dictates adaptive immune responses. Nature 569, 126-130 (2019).

75. Toivonen, R. et al. Activation of plasmacytoid dendritic cells in colon-draining lymph nodes during Citrobacter rodentium infection involves pathogen-sensing and inflammatory pathways distinct from conventional dendritic cells. J. Immunol. 196, 4750-4759 (2016).

76. Sun, C. M. et al. Small intestine lamina propria dendritic cells promote de novo generation of Foxp3 T reg cells via retinoic acid. J. Exp. Med. 204, 1775-1785 (2007).

77. Coombes, J. L. et al. A functionally specialized population of mucosal CD103+ DCs induces Foxp3+ regulatory $T$ cells via a TGF-beta and retinoic aciddependent mechanism. J. Exp. Med. 204, 1757-1764 (2007).

78. Jaensson-Gyllenback, E. et al. Bile retinoids imprint intestinal CD103+ dendritic cells with the ability to generate gut-tropic T cells. Mucosal Immunol. 4, 438-447 (2011).
79. Jaensson, E. et al. Small intestinal CD103+ dendritic cells display unique functional properties that are conserved between mice and humans. J. Exp. Med. 205, 2139-2149 (2008).

80. Esterhazy, D. et al. Classical dendritic cells are required for dietary antigenmediated induction of peripheral Treg cells and tolerance. Nat. Immunol. 17, 545-555 (2016).

81. Veenbergen, S. et al. Colonic tolerance develops in the iliac lymph nodes and can be established independent of CD103(+) dendritic cells. Mucosal Immunol. 9, 894-906 (2016).

82. Worthington, J. J., Czajkowska, B. I., Melton, A. C. \& Travis, M. A. Intestinal dendritic cells specialize to activate transforming growth factor-beta and induce Foxp3+ regulatory T cells via integrin alphavbeta8. Gastroenterology 141, 1802-1812 (2011).

83. Hung, L. Y. et al. Cellular context of IL-33 expression dictates impact on antihelminth immunity. Sci. Immunol. 5, eabc6259 (2020).

84. McDonald, K. G. et al. Epithelial expression of the cytosolic retinoid chaperone cellular retinol binding protein II is essential for in vivo imprinting of local gut dendritic cells by lumenal retinoids. Am. J. Pathol. 180, 984-997 (2012).

85. Zeng, R., Bscheider, M., Lahl, K., Lee, M. \& Butcher, E. C. Generation and transcriptional programming of intestinal dendritic cells: essential role of retinoic acid. Mucosal Immunol. 9, 183-193 (2016).

86. Rimoldi, M. et al. Intestinal immune homeostasis is regulated by the crosstalk between epithelial cells and dendritic cells. Nat. Immunol. 6, 507-514 (2005).

87. Chng, S. H. et al. Ablating the aryl hydrocarbon receptor (AhR) in CD11c+ cells perturbs intestinal epithelium development and intestinal immunity. Sci. Rep. 6, 23820 (2016).

88. Newberry, R. D., McDonough, J. S., Stenson, W. F. \& Lorenz, R. G. Spontaneous and continuous cyclooxygenase-2-dependent prostaglandin E2 production by stromal cells in the murine small intestine lamina propria: directing the tone of the intestinal immune response. J. Immunol. 166, 4465-4472 (2001).

89. Delgado, M., Gonzalez-Rey, E. \& Ganea, D. The neuropeptide vasoactive intestinal peptide generates tolerogenic dendritic cells. J. Immunol. 175, 7311-7324 (2005).

90. Singh, N. et al. Activation of Gpr109a, receptor for niacin and the commensal metabolite butyrate, suppresses colonic inflammation and carcinogenesis. Immunity 40, 128-139 (2014).

91. Cording, S. et al. The intestinal micro-environment imprints stromal cells to promote efficient Treg induction in gut-draining lymph nodes. Mucosal Immunol. 7, 359-368 (2014).

92. Hammerschmidt, S. I. et al. Stromal mesenteric lymph node cells are essential for the generation of gut-homing T cells in vivo. J. Exp. Med. 205, 2483-2490 (2008).

93. den Haan, J. M., Lehar, S. M. \& Bevan, M. J. CD8(+) but not CD8(-) dendritic cells cross-prime cytotoxic T cells in vivo. J. Exp. Med. 192, 1685-1696 (2000).

94. Dudziak, D. et al. Differential antigen processing by dendritic cell subsets in vivo. Science 315, 107-111 (2007)

95. Hildner, K. et al. Batf3 deficiency reveals a critical role for CD8alpha+ dendritic cells in cytotoxic T cell immunity. Science 322, 1097-1100 (2008).

96. Joeris, $T$. et al. Intestinal CDC1 drive cross-tolerance to epithelial-derived antigen via induction of FoxP3(+)CD8(+) T(regs). Sci. Immunol. 6, eabd3774 (2021).

97. Welty, N. E. \& et al. Intestinal lamina propria dendritic cells maintain T cell homeostasis but do not affect commensalism. J. Exp. Med. 210, 2011-2024 (2013).

98. Ferris, S. T. et al. CDC1 prime and are licensed by CD4(+) T cells to induce antitumour immunity. Nature 584, 624-629 (2020).

99. Laffont, S., Siddiqui, K. R. \& Powrie, F. Intestinal inflammation abrogates the tolerogenic properties of MLN CD103+ dendritic cells. Eur. J. Immunol. 40, 1877-1883 (2010).

100. Uematsu, S. et al. Regulation of humoral and cellular gut immunity by lamina propria dendritic cells expressing Toll-like receptor 5. Nat. Immunol. 9, 769-776 (2008).

101. Cerovic, V. et al. Hyporesponsiveness of intestinal dendritic cells to TLR stimulation is limited to TLR4. J. Immunol. 182, 2405-2415 (2009).

102. Mashayekhi, M. et al. CD8alpha(+) dendritic cells are the critical source of interleukin-12 that controls acute infection by Toxoplasma gondii tachyzoites. Immunity 35, 249-259 (2011).

103. Chudnovskiy, A. et al. Host-protozoan interactions protect from mucosal infections through activation of the inflammasome. Cell 167, 444-456 e414 (2016).

104. Sun, T. et al. Intestinal Batf3-dependent dendritic cells are required for optimal antiviral T-cell responses in adult and neonatal mice. Mucosal Immunol. 10, 775-788 (2017).

105. Pool, L., Rivollier, A. \& Agace, W. W. Deletion of IRF4 in dendritic cells leads to delayed onset of T cell-dependent colitis. J. Immunol. 204, 1047-1055 (2020).

106. Pohl, J. M. et al. Irf4-dependent $C D 103(+) C D 11 b(+)$ dendritic cells and the intestinal microbiome regulate monocyte and macrophage activation and intestinal peristalsis in postoperative ileus. Gut 66, 2110-2120 (2017). 
107. Panea, C. et al. Intestinal monocyte-derived macrophages control commensalspecific Th17 responses. Cell Rep. 12, 1314-1324 (2015).

108. Leonardi, I. et al. CX3CR1(+) mononuclear phagocytes control immunity to intestinal fungi. Science 359, 232-236 (2018).

109. Aychek, T. et al. IL-23-mediated mononuclear phagocyte crosstalk protects mice from Citrobacter rodentium-induced colon immunopathology. Nat. Commun. 6, 6525 (2015).

110. Friedrich, C. et al. MyD88 signaling in dendritic cells and the intestinal epithelium controls immunity against intestinal infection with $C$. rodentium. PLoS Pathog. 13, e1006357 (2017).

111. Phythian-Adams, A. T. et al. CD11c depletion severely disrupts Th2 induction and development in vivo. J. Exp. Med. 207, 2089-2096 (2010).

112. Mayer, J. U. et al. Different populations of $\mathrm{CD} 11 \mathrm{~b}(+)$ dendritic cells drive Th2 responses in the small intestine and colon. Nat. Commun. 8, 15820 (2017).

113. Gao, Y. et al. Control of $\mathrm{T}$ helper 2 responses by transcription factor IRF4dependent dendritic cells. Immunity 39, 722-732 (2013).

114. Flores-Langarica, $A$. et al. Intestinal $C D 103(+) C D 11 b(+)$ CDC2 conventional dendritic cells are required for primary CD4( + ) T and B cell responses to soluble flagellin. Front. Immunol. 9, 2409 (2018).

115. Flores-Langarica, A. et al. CD103(+)CD11b(+) mucosal classical dendritic cells initiate long-term switched antibody responses to flagellin. Mucosal Immunol. 11, 681-692 (2018)

116. Nakawesi, J. et al. alphavbeta8 integrin-expression by BATF3-dependent dendritic cells facilitates early IgA responses to Rotavirus. Mucosal Immunol. 14, 53-67 (2021).

117. Morbe, U. M. et al. Human gut-associated lymphoid tissues (GALT); diversity, structure, and function. Mucosal Immunol. 14, 793-802 (2021).

118. Buettner, M. \& Lochner, M. Development and function of secondary and tertiary lymphoid organs in the small intestine and the colon. Front. Immunol. 7, 342 (2016).

119. Bouskra, D. et al. Lymphoid tissue genesis induced by commensals through NOD1 regulates intestinal homeostasis. Nature 456, 507-510 (2008).

120. Kiss, E. A. et al. Natural aryl hydrocarbon receptor ligands control organogenesis of intestinal lymphoid follicles. Science 334, 1561-1565 (2011).

121. Lee, J. S. et al. AHR drives the development of gut ILC22 cells and postnatal lymphoid tissues via pathways dependent on and independent of Notch. Nat. Immunol. 13, 144-1451 (2011).

122. Lorenz, R. G., Chaplin, D. D., McDonald, K. G., McDonough, J. S. \& Newberry, R. D. Isolated lymphoid follicle formation is inducible and dependent upon lymphotoxin-sufficient B lymphocytes, lymphotoxin beta receptor, and TNF receptor I function. J. Immunol. 170, 5475-5482 (2003).

123. Pabst, O. et al. Cryptopatches and isolated lymphoid follicles: dynamic lymphoid tissues dispensable for the generation of intraepithelial lymphocytes. Eur. J. Immunol. 35, 98-107 (2005).

124. Fenton, T. M. et al. Immune profiling of human gut-associated lymphoid tissue identifies a role for isolated lymphoid follicles in priming of region-specific immunity. Immunity 52, 557-570.e556 (2020).

125. Tsuji, M. et al. Requirement for lymphoid tissue-inducer cells in isolated follicle formation and $\mathrm{T}$ cell-independent immunoglobulin $\mathrm{A}$ generation in the gut. Immunity 29, 261-271 (2008).

126. Hamada, $H$. et al. Identification of multiple isolated lymphoid follicles on the antimesenteric wall of the mouse small intestine. J. Immunol. 168, 57-64 (2002).

127. Kanamori, Y. et al. Identification of novel lymphoid tissues in murine intestinal mucosa where clusters of c-kit + IL-7R+ Thy1+ lympho-hemopoietic progenitors develop. J. Exp. Med. 184, 1449-1459 (1996).

128. Guendel, F. et al. Group 3 innate lymphoid cells program a distinct subset of IL22BP-producing dendritic cells demarcating solitary intestinal lymphoid tissues. Immunity 53, 1015-1032 e1018 (2020).

129. Jinnohara, T. et al. IL-22BP dictates characteristics of Peyer's patch follicleassociated epithelium for antigen uptake. J. Exp. Med. 214, 1607-1618 (2017).

130. Reboldi, A. et al. IgA production requires B cell interaction with subepithelial dendritic cells in Peyer's patches. Science 352, aaf4822 (2016).

131. Kunimura, K. et al. S100A4 protein is essential for the development of mature microfold cells in Peyer's patches. Cell Rep. 29, 2823-2834 e2827 (2019).

132. Harada, Y. et al. DOCK8 is a Cdc42 activator critical for interstitial dendritic cell migration during immune responses. Blood 119, 4451-4461 (2012).

133. Krishnaswamy, J. K. et al. Migratory $\mathrm{CD} 11 \mathrm{~b}(+)$ conventional dendritic cells induce T follicular helper cell-dependent antibody responses. Sci. Immunol. 2, eaam9169 (2017)

134. Krishnaswamy, J. K. et al. Coincidental loss of DOCK8 function in NLRP10deficient and $\mathrm{C} 3 \mathrm{H} / \mathrm{HeJ}$ mice results in defective dendritic cell migration. Proc. Natl Acad. Sci. USA 112, 3056-3061 (2015).
135. Bhalla, D. K. \& Owen, R. L. Cell renewal and migration in lymphoid follicles of Peyer's patches and cecum-an autoradiographic study in mice. Gastroenterology 82, 232-242 (1982)

136. Pappo, J. \& Owen, R. L. Absence of secretory component expression by epithelial cells overlying rabbit gut-associated lymphoid tissue. Gastroenterology 95, 1173-1177 (1988).

137. Kolesnikov, M. et al. Intravital visualization of interactions of murine Peyer's patch-resident dendritic cells with M cells. Eur. J. Immunol. 50, 537-547 (2020).

138. Lelouard, H., Fallet, M., de Bovis, B., Meresse, S. \& Gorvel, J. P. Peyer's patch dendritic cells sample antigens by extending dendrites through $\mathrm{M}$ cell-specific transcellular pores. Gastroenterology 142, 592-601 e593 (2012).

139. Lelouard, $\mathrm{H}$. et al. Pathogenic bacteria and dead cells are internalized by a unique subset of Peyer's patch dendritic cells that express lysozyme. Gastroenterology 138, 173-184 e171 (2010).

140. Disson, O. et al. Peyer's patch myeloid cells infection by Listeria signals through gp38(+) stromal cells and locks intestinal villus invasion. J. Exp. Med. 215, 2936-2954 (2018).

141. Revaud, J. et al. Firewalls prevent systemic dissemination of vectors derived from human adenovirus type 5 and suppress production of transgene-encoded antigen in a murine model of oral vaccination. Front. Cell. Infect. Microbiol. 8, 6 (2018).

142. Rochereau, N. et al. Dectin-1 is essential for reverse transcytosis of glycosylated SlgA-antigen complexes by intestinal M cells. PLoS Biol. 11, e1001658 (2013).

143. Sakhon, O. S. et al. M cell-derived vesicles suggest a unique pathway for transepithelial antigen delivery. Tissue Barriers 3, e1004975 (2015).

144. Knoop, K. A. et al. RANKL is necessary and sufficient to initiate development of antigen-sampling $M$ cells in the intestinal epithelium. J. Immunol. 183, 5738-5747 (2009).

145. Rios, D. et al. Antigen sampling by intestinal $M$ cells is the principal pathway initiating mucosal IgA production to commensal enteric bacteria. Mucosal Immunol. 9, 907-916 (2016).

146. Martinez-Lopez, M. et al. Microbiota sensing by Mincle-Syk axis in dendritic cells regulates interleukin-17 and -22 production and promotes intestinal barrier integrity. Immunity 50, 446-461 e449 (2019).

147. Kim, S. H., Cho, B. H., Kim, K. S. \& Jang, Y. S. Complement C5a promotes antigen cross-presentation by Peyer's patch monocyte-derived dendritic cells and drives a protective CD8(+) T cell response. Cell Rep. 35, 108995 (2021).

148. Durand, M. et al. Human lymphoid organ CDC2 and macrophages play complementary roles in T follicular helper responses. J. Exp. Med. 216, 1561-1581 (2019).

\section{ACKNOWLEDGEMENTS}

C.L. and H.L. thank J.P. Gorvel for helpful discussion. They were supported by institutional funding from Centre National de la Recherche Scientifique and Institut National de la Santé et de la Recherche Médicale, by the Fondation pour la Recherche Médicale (FRM), grant number DEQ20170336745 and by the Agence Nationale de la Recherche, grant number ANR-20-CE15-0016. F.T.H. and V.C. are supported by the German Research Foundation (DFG) grants DFG CE 345/1-1 and Project-ID 403224013 - SFB 1382 (B03).

\section{AUTHOR CONTRIBUTIONS}

All authors contributed equally to this review. C.L. designed the figure.

\section{COMPETING INTERESTS}

The authors declare no competing interests.

\section{ADDITIONAL INFORMATION}

Correspondence and requests for materials should be addressed to V.C. or H.L.

Reprints and permission information is available at http://www.nature.com/ reprints

Publisher's note Springer Nature remains neutral with regard to jurisdictional claims in published maps and institutional affiliations. 